
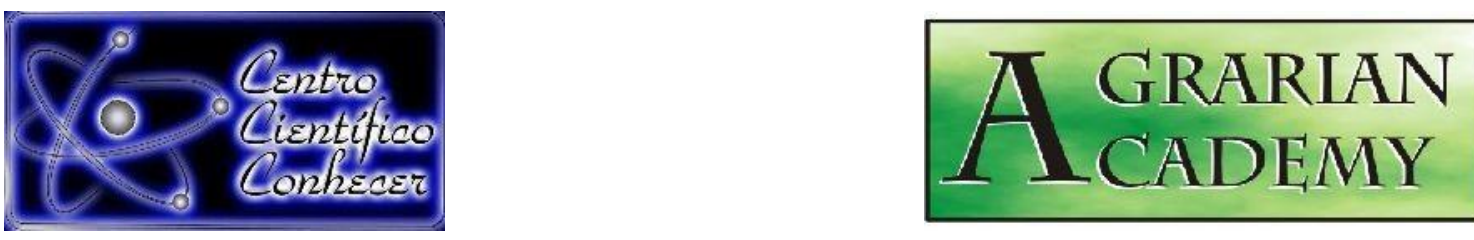

\title{
RELAÇÃO HIPSOMÉTRICA DE TRÊS ESPÉCIES DA CAATINGA, SEMIÁRIDO PERNAMBUCANO
}

Matheus Teixeira Martins ${ }^{1 *}$; Gabriel Paes Marangon²; Emanuel Arnoni Costa ${ }^{3}$; Maiquel Ivo Pfeifer"; Gerson dos Santos Lisboa ${ }^{5}$

1* Graduando em Engenharia Florestal, Universidade Federal do Pampa, São Gabriel, RS, Brasil (mteixeiramartins@gmail.com).

2 Prof. Dr. do Curso de Engenharia Florestal, Universidade Federal do Pampa, São Gabriel, RS, Brasil.

3 Prof. Dr. do Curso de Engenharia Florestal, Universidade Federal de Uberlândia, Monte Carmelo, MG, Brasil.

${ }^{4}$ Graduando em Engenharia Florestal, Universidade Federal do Pampa, São Gabriel, RS, Brasil

${ }^{5}$ Professor Dr. do Curso de Engenharia Florestal, Universidade Federal da Bahia, Itabuna, BA, Brasil.

Recebido em: 01/04/2020 - Aprovado em: 10/06/2020 - Publicado em: 30/07/2020 DOI: 10.18677/Agrarian_Academy_2020a5

\begin{abstract}
RESUMO
A Caatinga apresenta espécies com características diversificadas para sobrevivência, com mais de 100 espécies endêmicas, sendo de grande importância para o país. Encontra-se degradada devido à substituição de suas espécies nativas por cultivos agrícolas e pastagens. São poucos os trabalhos realizados sobre a vegetação desse bioma. A variável altura é essencial nos inventários florestais, porém sua mensuração é onerosa. Uma alternativa para que se tenha redução do custo é o uso de modelos hipsométricos. Com a importância da Caatinga e de estimar a altura de árvores, este estudo teve como objetivo estimar a altura de árvores por meio de modelos hipsométricos para três espécies de árvores presentes na Caatinga, Poincianella bracteosa (Tul.) L.P. Queiroz, Croton rhamnifolius H.B.K e Manihot glaziovii Muell. Arg. Foram ajustados 3 modelos para cada espécie e um único modelo reunindo todas as árvores das 3 espécies. A eficiência dos modelos foi avaliada por meio do coeficiente de determinação $\left(R^{2}\right)$, erro padrão da estimativa relativo (Syx\%) e análise gráfica dos resíduos. Os resultados obtidos mostraram que por meio de um mesmo modelo pode-se estimar alturas das árvores das três espécies sem ter perda de acurácia, com $\mathrm{R}^{2}$ de 0,28 e Syx\% 23,64\%.
\end{abstract}

PALAVRAS-CHAVE: Biometria florestal, Croton rhamnifolius, Inventário florestal, Manihot glaziovii, Poincianella bracteosa. 


\title{
HIPSOMETRIC RELATIONSHIP OF THREE SPECIES OF CAATINGA, SEMIARID PERNAMBUCANO
}

\begin{abstract}
The Caatinga presents species with diversified characteristics for survival, with more than 100 endemic species, being very importance for the country. It is degraded due to the replacement of its native species by agricultural crops and pastures. Few works have been done on the vegetation of this biome. The variable height is essential in forest inventories, but its measurement is costly. An alternative to reduce costs is the use of hypsometric models. With the importance of the Caatinga and to estimate the height of trees, this study aimed to estimate the height of trees by means of hypsometric models for three species of Caatinga, Poincianella bracteosa (Tul.) Queiroz, Croton rhamnifolius H.B.K and Manihot glaziovii Muell. Arg. Three models were adjusted for each species and for the total set of trees of the three species. The efficiency of the models was evaluated by means of the coefficient of determination $\left(\mathrm{R}^{2}\right)$, standard error of the relative estimation (Syx\%) and graphical analysis of the residues. The results showed that by means of the same model we can estimate tree heights of the 3 species without loss of accuracy, with $R^{2}$ of 0.28 and Syx\% 23.64\%.
\end{abstract}

KEYWORDS: Croton rhamnifolius, Forest biometry, Forest inventory, Manihot glaziovii, Poincianella bracteosa.

\section{INTRODUÇÃO}

O Bioma Caatinga abrange cerca de $900 \mathrm{mil} \mathrm{Km}^{2}$, que correspondem a aproximadamente $54 \%$ da Região Nordeste, presente em partes dos estados: norte de Minas Gerais, interior da Bahia, sudoeste do Piauí, Ceará, Rio Grande do Norte, Paraíba, Pernambuco, Alagoas e Sergipe (ANDRADE et al., 2005).

A Caatinga é um complexo de vegetação com formação de espécies herbáceas, arbustivas e arbóreas de pequeno porte, principalmente, espécies com presença de espinhos e caducifólias e apresentam características especiais para sobrevivência às condições adversas de clima e solo, típicos desta fisionomia (ARAÚJO FILHO, 2013).

Os ecossistemas da Caatinga apresentam-se bastante alterados com a substituição da vegetação nativa por cultivos e pastagens, utilizando metodologias rudimentares no preparo do solo como o desmatamento seguido pela queimada, prejudicando a manutenção das populações da fauna silvestre, qualidade da água e o equilíbrio do clima e do solo (MEDEIROS et al., 2018).

$\mathrm{Na}$ realização de inventários florestais, a altura é uma variável de grande importância, principalmente quando se tem o objetivo de estimar o volume de madeira ou a verificação da qualidade de sítio. Tendo em vista que é inviável medir a altura de todas as árvores na floresta, por questões de custo de inventário florestal, é necessário realizar estimativas, baseado nas alturas obtidas de algumas árvores e outras variáveis, como o diâmetro à altura do peito (dap). Uma das maneiras de se obter as estimativas de altura é a utilização de modelos matemáticos, sendo que essa técnica já tem o uso consagrado. Dentre os modelos matemáticos, tem-se grande uso de modelos hipsométricos, como é visto em Andrade et al. (2015), Machado et al. (2019), Martins et al. (2019) entre outros.

Modelos hipsométricos têm a função de expressar a relação entre altura e diâmetro e assim são obtidas estimativas bastante eficientes da altura das árvores. Porém deve-se ter o conhecimento de que os padrões hipsométricos se distinguem 
em diferentes tipologias florestais, assim como, em uma mesma tipologia florestal para distintos sítios, e ainda, dentro do mesmo sitio, em virtude da heterogeneidade ambiental e estrutural, havendo divergentes relações hipsométricas (BATISTA et al., 2014). Portanto devem ser testados mais de um modelo hipsométrico e a partir de suas estatísticas de ajustes, selecionar o melhor, que irá gerar estimativas mais acuradas, possibilitando assim que o mesmo seja aplicado para ambientes desejados e em outros que apresentem condições iguais ou semelhantes.

Gerar equações com confiabilidade estatística para estimar a relação hipsométrica, bem como, a distribuição diamétrica de espécies florestais é de extrema importância para o manejo sustentável das florestas nativas. Principalmente, devido à dificuldade de encontrar a relação entre o diâmetro e a altura correspondente do fuste, pois em muitos casos, as árvores apresentam uma porção de tronco pouco aproveitável, ou disforme, o que ocasiona a presença de valores altos em diâmetros e baixos em altura, sendo o contrário também verificado (HESS et al., 2014).

Face ao exposto sobre a importância do bioma Caatinga e do conhecimento da altura das árvores principalmente no que diz respeito a ambientes com grande heterogeneidade florística e estrutural, além disso, devido a presença de indivíduos multifustes, o presente estudo teve como objetivo estimar a altura de três espécies de árvores presentes na Caatinga no munícipio de Floresta no estado de Pernambuco por meio do ajuste de três modelos hipsométricos, para cada espécie e para o conjunto das três espécies e assim verificar se apenas um modelo poderia estimar a altura das árvores com acurácia.

\section{Caracterização da área de estudo}

\section{MATERIAIS E MÉTODOS}

A área de estudo foi composta por duas áreas com distância de $300 \mathrm{~m}$ entre cada uma, no município de Floresta, PE. A área 1 com 10 ha, apresentava um melhor estado de conservação, apesar de ser notável a presença de ação antrópica, como, exploração madeireira e pastejo por caprinos. A área $2 \mathrm{com} 20$ ha também apresentava ação antrópica, além disso, tinha histórico de perturbação, há aproximadamente 20 anos, onde foi feito corte raso com uso de correntão e roças de algodão.

De acordo com a classificação de Köppen, o clima é do tipo Tropical Semiárido, apresentando-se como BSh', com chuvas de verão. A precipitação média anual é de $431,8 \mathrm{~mm}$ e a temperatura média é de 24,7 ํㅡ (CPRM, 2005). O solo presente na área de estudo é classificado como, Luvissolo Crômico pouco profundo, com textura superficial arenosa a média (EMBRAPA, 2018).

\section{Obtenção dos dados}

Na Figura 1 é apresentado um esquema ilustrando a localização e distribuição das unidades amostrais, sendo que, na área 1 foram instaladas 20 parcelas e na área 2, 30 parcelas. As parcelas apresentavam área de $400 \mathrm{~m}^{2}(20 \times 20 \mathrm{~m})$ e foram distribuídas de forma sistemática, com distância de $80 \mathrm{~m}$ entre linhas e entre parcelas.

Todas as árvores com circunferência a altura do peito (cap) com medida igual ou superior a $6,0 \mathrm{~cm}$ foram mensuradas. As alturas foram obtidas com uso de régua graduada. Foi realizada a seleção das três espécies com maior número de indivíduos, sendo: Poincianella bracteosa, Croton rhamnifolius e Manihot glaziovii, 
conhecidas popularmente como, catingueira, quebra-faca e maniçoba, respectivamente, resultando em 2239 observações.

FIGURA 1- Localização e distribuição das unidades amostrais na área de estudo no município de Floresta - PE.

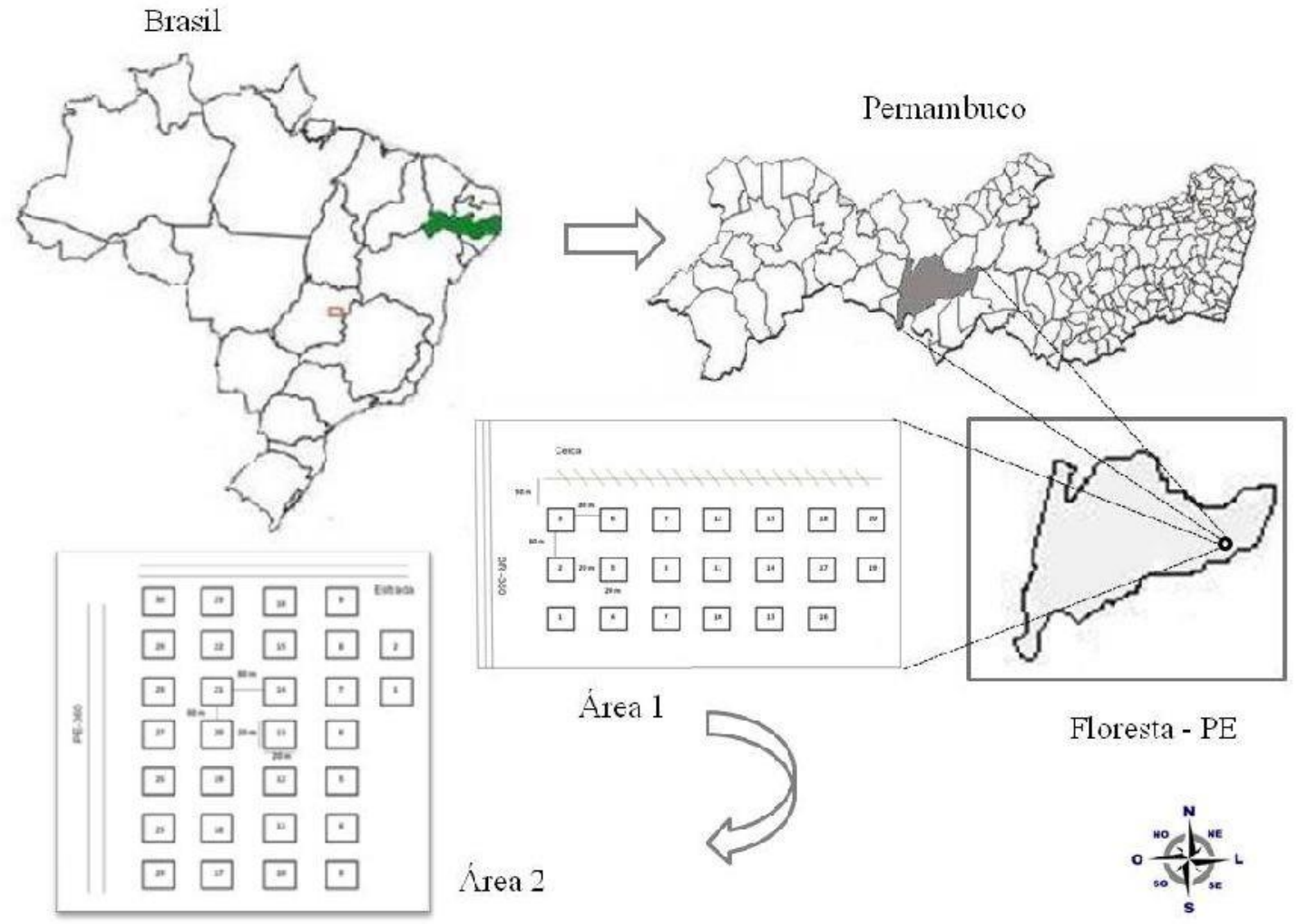

Fonte: Autores (2020).

\section{Manipulação dos dados}

Os dados obtidos de cap foram transformados em dap, para que assim se tivesse a relação entre a altura em metros e dap em $\mathrm{cm}$ (relação h.d ${ }^{-1}$ ). Foram ajustados três modelos (Quadro 1) para estimar a altura das árvores para cada espécie e para o conjunto de dados total, composto por todos os indivíduos. Para isso foi utilizada a função de regressão na planilha eletrônica Excel (MICROSOFT® OFFICE, 2016). Os modelos foram ajustados para cada espécie e para o conjunto das três espécies.

Para verificar o melhor modelo para estimar a altura das árvores foram considerados os seguintes critérios: coeficiente de determinação $\left(R^{2}\right)$, erro padrão da estimativa relativo (Syx\%) e análise gráfica dos resíduos. 
QUADRO 1- Modelos hipsométricos ajustados para estimar a altura das árvores das três espécies da Caatinga presentes na área do estudo no município de Floresta, PE.

\begin{tabular}{cc}
\hline Modelo & Equação \\
\hline 1 & $h=\beta_{0}+\beta_{1} \cdot$ dap $^{2}$ \\
2 & $h=\beta_{0}+\beta_{1} .1 /$ dap $+\varepsilon$ \\
3 & $h=\beta_{0}+\beta_{1} \cdot \ln ($ dap $)+\varepsilon$
\end{tabular}

Em que: $\beta_{0}, \beta_{1}=$ coeficientes do modelo, $h=$ altura $(m)$, dap = diâmetro à altura do peito.

Fonte: Autores (2020).

\section{RESULTADOS}

A espécie Poincianella bracteosa apresentou o maior número de indivíduos na área, com 2080 árvores, foi verificado o diâmetro mínimo de $1,9 \mathrm{~cm}$, sendo o máximo de $15,6 \mathrm{~cm}$ e o diâmetro médio de $3,8 \mathrm{~cm}$. A altura mínima foi de $1,5 \mathrm{~m}$, sendo a altura máxima de 7,0 $\mathrm{m}$ e a altura média de 3,5 $\mathrm{m}$. Essa espécie apresentou o maior diâmetro máximo e a maior altura máxima, assim como, a espécie Manihot glaziovii, apresentou a altura máxima de $7,0 \mathrm{~m}$, a altura mínima foi maior quando comparada as outras duas espécies, alcançando 2,2 m, em relação ao diâmetro, foi observado, diâmetro mínimo de 2,1 cm e máximo de $14,0 \mathrm{~cm}$, resultado próximo ao observado na espécie Poincianella bracteosa. Para essa espécie foram mensurados 116 indivíduos. A espécie com as menores dimensões foi a Croton rhamnifolius, que apresentou diâmetro mínimo de $1,9 \mathrm{~cm}$, o diâmetro médio $2,6 \mathrm{~cm}$ e diâmetro máximo de $5,4 \mathrm{~cm}$, em relação à altura, foi verificada a altura mínima de $1,5 \mathrm{~m}$, média $2,9 \mathrm{~m}$ e a máxima de 5,2 $\mathrm{m}$. Essa espécie apresentou a segunda maior quantidade de indivíduos, sendo mensuradas 603 árvores (Tabela 1).

TABELA 1- Estatística descritiva das variáveis altura $(\mathrm{m})$ e dap $(\mathrm{cm})$ para as três espécies da Caatinga no munícipio de Floresta, PE.

\begin{tabular}{|c|c|c|c|c|c|}
\hline Espécie & Variável & Mínimo & Média & Máximo & CV\% \\
\hline \multirow{2}{*}{$\begin{array}{c}\text { Poincianella } \\
\text { bracteosa } \\
(\mathrm{n}=1662)\end{array}$} & dap & 1,9 & 3,8 & 15,6 & 39,6 \\
\hline & $\mathrm{h}$ & 1,5 & 3,5 & 7,0 & 26,5 \\
\hline \multirow{2}{*}{$\begin{array}{c}\text { Croton rhamnifolius } \\
(\mathrm{n}=484)\end{array}$} & dap & 1,9 & 2,6 & 5,4 & 19,5 \\
\hline & $\mathrm{h}$ & 1,5 & 2,9 & 5,2 & 24,6 \\
\hline \multirow{2}{*}{$\begin{array}{l}\text { Manihot glaziovii } \\
(\mathrm{n}=93)\end{array}$} & dap & 2,1 & 6,7 & 14,0 & 38,4 \\
\hline & $\mathrm{h}$ & 2,2 & 4,5 & 7,0 & 22,2 \\
\hline \multirow{2}{*}{ Todos $(\mathrm{n}=2239)$} & dap & 1,9 & 3,6 & 15,6 & 44,4 \\
\hline & $\mathrm{h}$ & 1,5 & 3,4 & 7,0 & 27,8 \\
\hline
\end{tabular}

Em que: $\mathrm{CV} \%$ = Coeficiente de Variação.

Fonte: Autores (2020). 
Foi verificado com o ajuste dos modelos que os resultados estatísticos de $\mathrm{R}^{2}$ não foram muito elevados, como é visto em ajustes de modelos hipsométricos para espécies exóticas como eucalipto e pinus, corriqueiramente estudados, e que demonstram características mais desejáveis para este tipo de estudo (Tabela 2).

Resultados menores são comuns devido as espécies em estudo apresentarem características dendrométricas peculiares do Bioma Caatinga com adaptações aos severos períodos de seca, totalmente diferentes das encontradas em espécies exóticas, portanto, valores menores de $R^{2}$ não significam que os modelos não sejam eficientes, somente não apresentam um ajuste tão bom devido a desuniformidade das árvores. Os resultados obtidos indicam que o modelo 3 é o mais indicado para estimar a altura das árvores para as espécies Poincianella bracteosa, Manihot glaziovii e para o conjunto total de árvores das três espécies, alcançando $R^{2}$ de $0,213,0,315$ e 0,280 , respectivamente.

Em relação ao Syx\%, o modelo 3 apresentou $23,50 \%, 18,46 \%$ e $23,64 \%$, para as espécies Poincianella bracteosa, Manihot glaziovii e para todo o conjunto de árvores, respectivamente. Para espécie Croton rhamnifolius foi verificado que o modelo 1 foi o melhor para estimar a altura das árvores, com $\mathrm{R}^{2}$ de 0,025 e Syx\% de 24,28 , o Syx\% obtido com as estimativas realizadas com esse modelo foram mais elevados comparados as estimativas realizadas com o modelo três nas demais espécies e para o conjunto total.

Portanto, pode-se afirmar que utilizando apenas o modelo três foi possível estimar a altura das árvores para as três espécies da Caatinga, sem perder a acurácia nas estimativas.

TABELA 2- Coeficientes estimados dos modelos hipsométricos e suas estatísticas de ajuste para estimar a altura de cada uma das três espécies da Caatinga e para o conjunto das três espécies.

\begin{tabular}{cccccc}
\hline Equação & Espécies & $\boldsymbol{\beta}_{\mathbf{0}}$ & $\boldsymbol{\beta}_{\mathbf{1}}$ & $\mathbf{R}^{\mathbf{2}}$ & $\mathbf{S y x} \%$ \\
\hline 1 & \multirow{2}{*}{ Poincianella } & 3,1060 & 0,0250 & 0,188 & 23,88 \\
2 & bracteosa & 4,7750 & $-4,2090$ & 0,188 & 23,88 \\
3 & 1,9503 & 1,2394 & 0,213 & 23,50 \\
\hline 1 & \multirow{2}{*}{ Croton rhamnifolius } & 2,6417 & 0,0358 & 0,025 & 24,28 \\
2 & 3,5232 & $-1,5887$ & 0,020 & 24,34 \\
3 & & 2,3136 & 0,6170 & 0,023 & 24,31 \\
\hline 1 & \multirow{2}{*}{ Manihot glaziovii } & 3,7893 & 0,0134 & 0,261 & 19,17 \\
2 & & 2,5814 & $-6,2083$ & 0,289 & 18,81 \\
3 & & 2,0561 & 1,3297 & 0,315 & 18,46 \\
\hline 1 & \multirow{2}{*}{ Todos } & 3,0154 & 0,0256 & 0,235 & 24,36 \\
2 & & 4,8877 & $-4,6516$ & 0,249 & 24,14 \\
3 & & 1,7667 & 1,3605 & 0,280 & 23,64 \\
\hline
\end{tabular}

Fonte: Autores (2020).

Na Figura 2 são apresentadas as representações gráficas de altura observada versus altura estimada, ambas em metros em função do dap em centímetros e a distribuição residual em porcentagem em função do dap para os melhores modelos validados para as três espécies da Caatinga. 
FIGURA 2- Alturas observadas e estimadas (h) em função do dap (A, C, E, G) e distribuição residual em porcentagem em função do dap $(B, D, F, H)$ para os melhores modelos validados para as três espécies da Caatinga.
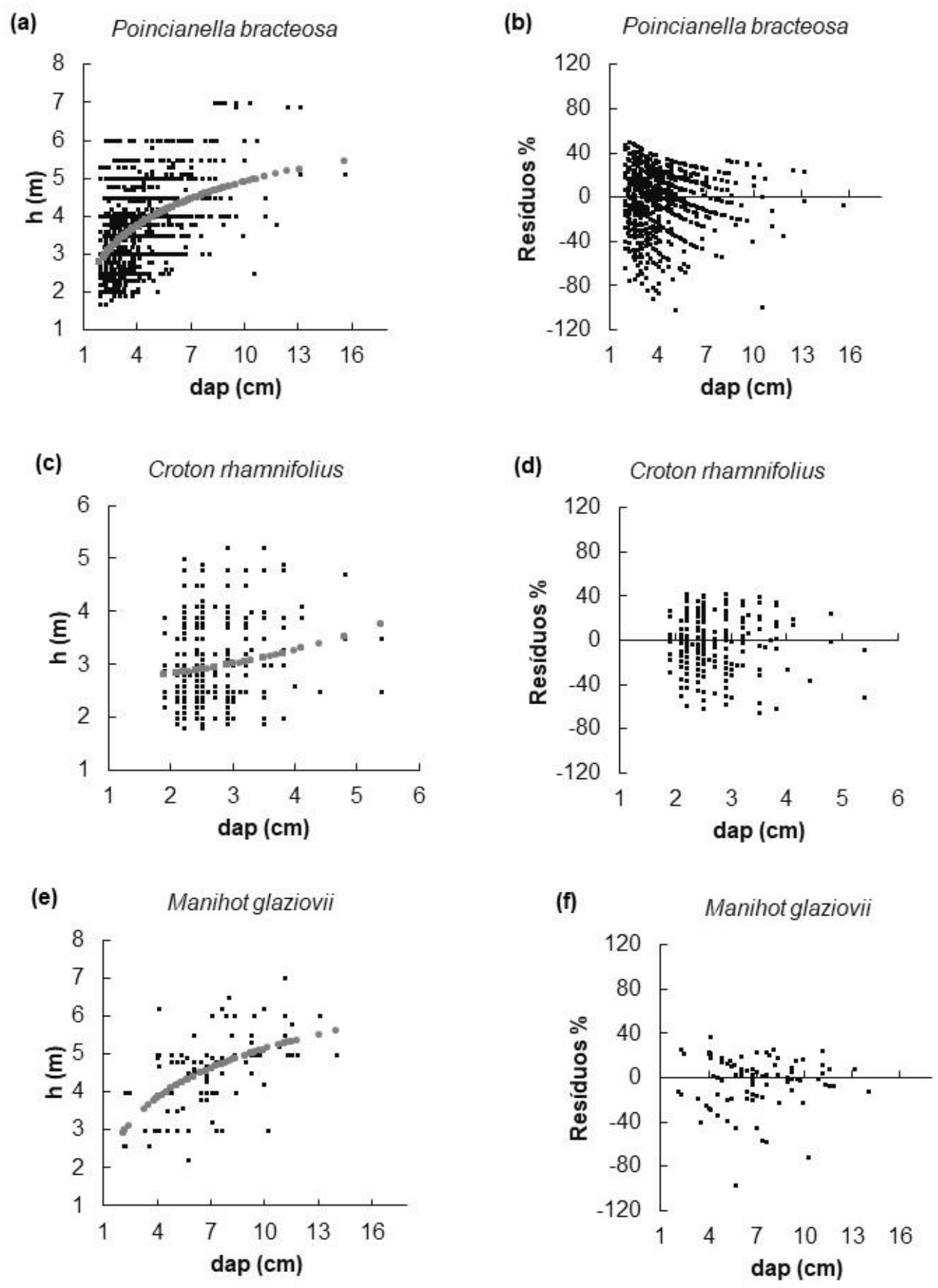
(g)

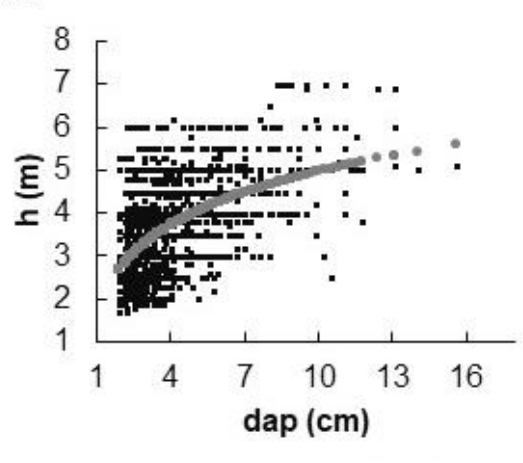

- Observado - Estimado (h)

(h) Todos

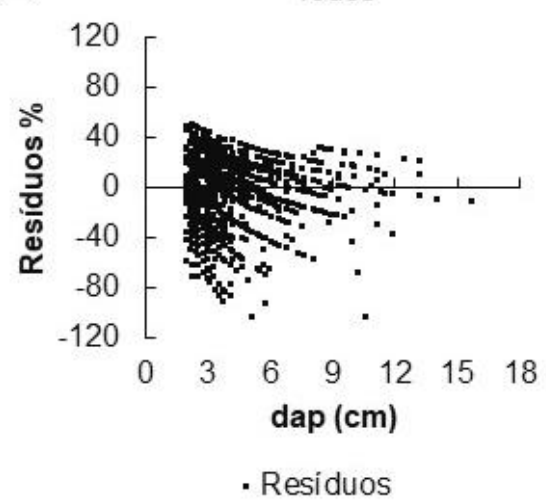

Fonte: Autores (2020).

As representações gráficas apresentam um comportamento semelhante na nuvem de pontos de alturas estimadas e também para a distribuição residual em porcentagem para a espécie Poincianella bracteosa e para todo o conjunto de árvores. Para a espécie Poincianella bracteosa foi observado um intervalo da dispersão de resíduos variando de $-102,04 \%$ a 50,50\%, portando, a diferença entre intervalo foi de $-51,54 \%$, já para o conjunto total de árvores das três espécies foi verificado um intervalo variando entre $-102,11 \%$ e $51,93 \%$, portando, a diferença foi de $-50,17 \%$.

Para as espécies Croton rhamnifolius e Manihot glaziovii os resultados foram bem diferentes. Para a espécie Croton rhamnifolius houve melhor dispersão de resíduos comparados aos resultados obtidos para as outras espécies e para o conjunto total de árvores, sendo que o intervalo de dispersão variou entre $-64,90 \%$ e $42,86 \%$, com a diferença de $-22,03 \%$ entre esses valores. Com relação ao gráfico de altura observada versus altura estimada em função do dap, foi observado que não houve bom recobrimento das alturas observadas pela nuvem de pontos de alturas estimadas. Portanto, as alturas estimadas com o modelo 1, confirmam os resultados de Syx\% que foram altos comparados aos resultados obtidos com o modelo 3 nas demais espécies e no conjunto total de árvores.

O gráfico de altura observada versus altura estimada em função do dap da espécie Manihot glaziovii foi o que apresentou o melhor recobrimento das alturas observadas através da nuvem de pontos de alturas estimadas, o melhor ajuste ocorreu devido ao menor número de árvores dessa espécie e o tamanho de dap e altura serem maiores comparados as demais espécies. Relacionado ao gráfico de dispersão residual foi verificado um intervalo de $-96,85 \%$ a $37,66 \%$, portanto diferença de $-59,19 \%$ entre intervalos.

As representações gráficas apresentam a eficiência dos melhores modelos ajustados para as espécies e para o conjunto total de árvores, proporcionando a análise mais detalhada dos resultados. Com essa análise foi possível confirmar que, mesmo que o modelo 1, tenha apresentado a melhor distribuição residual no ajuste para a espécie Croton rhamnifolius, ainda assim teve Syx\% elevado comparado aos demais modelos ajustados para as demais espécies e para o conjunto total de árvores. Porém, dentro do conjunto de árvores da espécie Croton rhamnifolius o modelo apresentou o menor Syx\%, porém, não muito inferior do que o resultado obtido para o modelo 3. 
Sendo assim, utilizando apenas o modelo 3 foi possível estimar a altura das árvores das três espécies da Caatinga, sem a necessidade de separar por espécies e além disso, pode ser estimada a altura dessas árvores em outras locais que apresentem características edafoclimáticas semelhantes.

\section{DISCUSSÃO}

Souza et al. (2017) realizaram um estudo com objetivo de ajustar modelos hipsométricos tradicionais para um povoamento de eucalipto híbrido na Amazônia brasileira, no munícipio de Pacajá no estado do Pará, com fins de indicar aquele(s) que melhor descreva $(\mathrm{m})$ a relação altura-diâmetro. Para isso foram testados 17 modelos hipsométricos de natureza aritmética e logarítmica, utilizando um conjunto de dados de 328 árvores, composto por medidas de altura $(\mathrm{m})$ e dap $(\mathrm{cm})$, foram separados do conjunto 50 pares de dados para serem utilizados como validação dos modelos. Os autores concluíram que os modelos mais eficientes foram, o modelo Hiperbólico que obteve coeficiente de determinação ajustado de 0,99 e erro padrão da estimativa de 0,08 e modelo de Naslund apresentou coeficiente de determinação ajustado de 0,99 e erro padrão da estimativa de 0,93, portanto modelo hiperbólico teve uma pequena vantagem devido ter menor valor de erro padrão da estimativa.

Motta et al. (2016) tiveram como objetivo em seu trabalho avaliar a modelagem linear e não linear para predição da altura total de árvores de Tectona grandis L. f (teca) em povoamentos jovens de origem clonal e seminal no município de Figueirópolis D'Oeste, Mato Grosso. Para isso, foram ajustados seis modelos hipsométricos, utilizando dados de altura $(\mathrm{m})$ e diâmetro à altura do peito $(\mathrm{cm})$ nas idades de 36 e 48 meses. A validação foi realizada baseada no teste do Quiquadrado, utilizando 20 árvores que não foram utilizadas no ajuste. Os autores concluíram que modelos lineares foram mais eficientes que os modelos não lineares, devido ao povoamento avaliado ser jovem e estar em plena fase de crescimento.

Cerqueira et al. (2017) realizaram um estudo com objetivo de avaliar o desempenho de modelos hipsométricos para estimar a altura de árvores de Tectona grandis no munícipio de São Francisco no estado do Pará, para isso, foram testados seis modelos hipsométricos utilizando dados de altura $(\mathrm{m})$ e dap $(\mathrm{cm})$ de 47 árvores com 10 anos de idade. Os autores concluíram que o modelo linear de Stoffels foi o mais acurado para estimar a altura das árvores de teca na área do estudo, apresentando coeficiente de determinação ajustado de 0,818 e Syx\% de 12,34\%, podendo ser utilizado em regiões com características semelhantes.

Mendonça et al. (2015) tiveram como objetivo em seu estudo avaliar modelos tradicionais e genéricos para estimar altura de árvores de Pinus caribaea var. hondurensis no munícipio de Nova Ponte no estado de Minas Gerais, para isso foram ajustados 10 modelos hipsométricos, utilizando dados de diferentes idades, sítios e densidades de plantio. Os autores verificaram que os modelos genéricos foram mais precisos em estimar as alturas das árvores.

Comparando os resultados obtidos nesse estudo com os resultados dos trabalhos citados são observados resultados mais eficientes, isso acontece pelas características de crescimento, sítio, melhoramento genético, fisiologia das espécies, entre outras, portanto, as características são totalmente diferentes para as espécies de ocorrência natural na Caatinga, assim, o ajuste de modelos para as espécies nativas torna-se mais difícil obter resultados mais precisos. Não se encontram na literatura trabalhos voltados para relação hipsométrica para as espécies avaliadas nesse estudo, portanto, para o futuro seria ideal realizar o ajuste de modelos mais complexos ou até mesmo utilizar outras técnicas como as Redes Neurais Artificiais 
(RNA) para verificar se ocorre a melhoria das estimativas da altura das árvores para essas espécies.

\section{CONCLUSÕES}

Com o uso de apenas um modelo hipsométrico foi possível estimar a altura das árvores para as três espécies da Caatinga. Além disso, a equação gerada poderá ser aplicada em locais com características semelhantes e contribuir para redução de custos e tempo em inventários florestais para fins científicos e de planos de manejo florestal neste Bioma.

\section{REFERÊNCIAS}

ANDRADE, L. A.; PEREIRA, I. M.; LEITE, U. T.; BARBOSA, M. R. V. Análise da cobertura de duas fitofisionomias de caatinga, com diferentes históricos de uso, no município de São João do Cariri, estado da Paraíba. Cerne, v.11, n.3, p.253-262, 2005.

http://www.cerne.ufla.br/site/index.php/CERNE/article/view/442.

ANDRADE, V. C. L. de; KROETZ, E. A.; NICOLA, A.; SOUZA, P. B. de; NOHAMA, F. $K$. et al. Amostragem e agrupamento de dados de relação hipsométrica em inventários florestais de Cerrado Tocantinense. Pesquisa Florestal Brasileira, v.35, n.83, p.228-238, 2015. Disponível em: https://pfb.cnpf.embrapa.br/pfb/index.php/pfb/article/view/683. DOI: https://doi.org/10.4336/2015.pfb.35.83.683.

ARAÚJO FILHO, J.A. Manejo pastoril sustentável da Caatinga. 1.ed. Recife, PE: Projeto Dom Helder Câmara, 2013. 200p.

BATISTA, J. L. F.; COUTO, H. T. Z., SILVA FILHO, D. F. Quantificação de recursos florestais: árvores, arvoredos e florestas. 1 ed. São Paulo: Oficina de Textos, 2014.

CERQUEIRA, C. L.; LISBOA, G. S.; FRANÇA, L. C. J.; MÔRA, R.; MARQUES, G. M. et al. Modelagem da altura e volume de Tectona grandis L.F. na mesorregião Nordeste do Pará. Nativa, Sinop, v.5, esp., p.606-611, 2017. Disponível em: http://periodicoscientificos.ufmt.br/ojs/index.php/nativa/article/view/5037. DOI: http://dx.doi.org/10.5935/2318-7670.v05nespa22.

CPRM - Serviço Geológico do Brasil. Projeto cadastro de fontes de abastecimento por água subterrânea. Diagnóstico do município de Floresta, estado de Pernambuco. Recife: CPRM/PRODEEM, 2005. 33p. Disponível em: http://rigeo.cprm.gov.br/xmlui/bitstream/handle/doc/15945/Rel_Floresta.pdf?sequenc $\mathrm{e}=1$.

EMBRAPA. Sistema brasileiro de classificação de solos. Brasília: EMBRAPA, 5. Ed. 2018, 356 p.

HESS, A. F.; BRAZ, E. M.; THAINES, F.; MATTOS, P. P. Ajuste de relação hipsométrica para espécies da Floresta Amazônica. Ambiência, v.10 n.1 p. 21-29, 2014. 
MACHADO, I. E. S.; MEDEIROS, P. C. A. O.; CARVALHO, M. G. C.; PEREZ, C.

A. M.; SANTANA, T. F. et al. Modelos hipsométricos ajustados para um fragmento de cerrado Sensu stricto tocantinense. Revista Agrogeoambiental, v.11, n.1, p. 155-167, 2019. Disponível em: https://agrogeoambiental.ifsuldeminas.edu.br/index.php/Agrogeoambiental/article/v iew/1174. DOI: http://dx.doi.org/10.18406/2316-1817v11n120191174.

MARTINS, M. T.; MARANGON, G. P.; COSTA, E. A.; PFEIFER, M. I.; SILVEIRA, B. D. da. Uso de diferentes técnicas para descrição da altura de um plantio

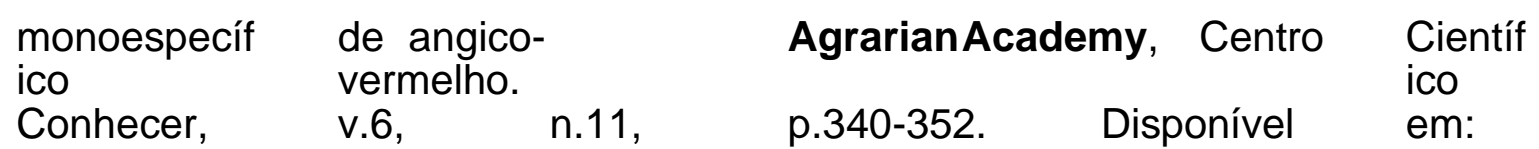
http://www.conhecer.org.br/Agrarian\%20Academy/2019A/uso\%20de\%20diferentes.p df DOI: http://dx.doi.org/10.18677/Agrarian_Academy_2019a32.

MEDEIROS, F. S.; SOUZA, M. P.; CERQUEIRA, C. L.; ALVES, A. R.; SOUZA, M. $S$. et al. Florística, fitossociologia e modelagem da distribuição diamétrica em um fragmento de caatinga em São Mamede-PB. ACSA, v.14, n.2, p.85-95, 2018. Disponível em: http://revistas.ufcg.edu.br/acsa/index.php/ACSA/article/view/900. DOI: http://dx.doi.org/10.30969/acsa.v14i2.900.

MENDONÇA, A. R.; CORANDIN, C. M.; PACHECO, G. R.; VIEIRA, G. C.; ARAÚJO, M. S. et al. Modelos hipsométricos tradicionais e genéricos para Pinus caribaea var. hondurensis. Pesquisa Florestal Brasileira, v. 35, n. 81, p. 47-54, 2015. Disponível em: $\quad$ https://pfb.cnpf.embrapa.br/pfb/index.php/pfb/article/view/710. DOI: https://doi.org/10.4336/2015.pfb.35.81.710.

MOTTA, A. S.; ALMEIDA, E. J.; VENDRUSCOLO, D. G. S.; SOUZA, H. S.; MEDEIROS, R. A. et al. Modelagem da altura de Tectona grandis L. f. clonal e seminal. Revista Brasileira de Biometria, v.34, n.3, p.395-406, 2016. Disponível em:https://www.researchgate.net/profile/Diogo_Vendruscolo/publication/308774588 MODELAGEM_DA_ALTURA_DE_Tectona_grandis_L_f_CLONAL_E_SEMINAL/link s/57ef1e0e08ae886b89740e5d/MODELAGEM-DA-ALTURA-DE-Tectona-grandis-L-fCLONAL-E-SEMINAL.pdf.

SOUZA, A. S.; SANTOS, J. X.; SOUZA, D. V. Modelagem da relação hipsométrica para um povoamento híbrido de eucalipto na Amazônia brasileira. BIOFIX Scientific Journal, $\quad$ v. $2, \quad$ n. $1, \quad 2017 . \quad$ Disponível em: https://revistas.ufpr.br/biofix/article/view/51395. DOI: http://dx.doi.org/10.5380/biofix.v2i1.51395. 